\title{
Clinical profile of mortality predictors in Leptospirosis:a prospective study in a tertiary care center
}

\author{
Arun Divakar ${ }^{1}$, M.G.K. Pillai ${ }^{2}$, Elizbeth Thomas ${ }^{3}$ \\ ${ }^{1}$ Dr. Arun Divakar, Assistant Professor, ${ }^{2}$ Dr. M. Gopala Krishna Pillai, HOD \& Professor, ${ }^{3}$ Dr. Elizabeth \\ Thomas, Post Graduate Student; all authors are affiliated with department of General Medicine, Amrita Institute \\ of Medical Sciences, Ponekkara Kochi, Kerala, India.
}

Address for Correspondence: Dr. M. Gopala Krishna Pillai, HOD \& Professor, Amrita Institute of Medical Sciences, Ponekkara, Kochi, Kerala, India. Email: mgkpillai@aims.amrita.edu

\begin{abstract}
Aims and Objectives: To look for mortality predictors of Leptospirosis, with specific importance given to oliguric renal failure and hypotension as possible predictors. Materials and Methods: A Prospective Cohort study conducted over two years which enrolled patients with clinically and serologically confirmed Leptospirosis. Of these, 30 patients were included who had hypotension and 30 patients who had oliguric renal failure, as per statistical requirements. Epidemiological, clinical, and laboratory data was collected at admission and the patients were followed up to look for outcome (discharge/death). Results: A total of 83 patients were included in this study. Of these 8 patients died (Mortality of 9.6\%). Data analysis with Chi Square Test showed that oliguric renal failure was significantly associated with mortality in Leptospirosis $(\mathbf{p}<0.05)$. Other factors were also found which were associated with mortality including elevated bilirubin and AST levels, anemia, Type 2 Diabetes Mellitus, Alcohol Dependence Syndrome, and Chronic Liver Disease. However, hypotension was found to not be significantly associated with mortality. Conclusion: In patients with Leptospirosis, significant mortality predictors included oliguric renal failure, elevated bilirubin and AST levels, anemia, Type 2 Diabetes Mellitus, Alcohol Dependence Syndrome, and Chronic Liver Disease.
\end{abstract}

Key words: Leptospirosis, Mortality Indicator, mortality predictors

\section{Introduction}

Leptospirosis is a zoonotic disease with global distribution which is responsible for significant mortality especially in the tropical regions. Recent data through developing surveillance programs now indicate it is possibly the most common zoonosis [1]. Geographic distribution shows predominance in south Asia, the Amazon Delta regions of South America and many island nations of the Indian and Pacific oceans [2]. Its manifestations range from asymptomatic to a severe form of Leptospirosis called Weil's disease, which usually accounts for $1-10 \%$ of leptospirosis cases of which there may be around 50,000 deaths $[3,4]$. This leads to an overall mortality rate of $10 \%$ for Leptospirosis $[2,5]$. The objective of this study is to assess the mortality predictors of

Manuscript received: $4^{\text {th }}$ September 2017

Reviewed: $14^{\text {th }}$ September 2017

Author Corrected: $20^{\text {th }}$ September 2017

Accepted for Publication: 26 $6^{\text {th }}$ September 2017
Leptospirosis, with the primary objective being to look for association between mortality in Leptospirosis and oliguric renal failure or hypotension at admission. Secondary objective was to assess if there is an association between any other epidemiological, clinical and biochemical factors at admission (e.g. Age, presenting complaint, potassium, etc.) and mortality in Leptospirosis. Once they have been confirmed, the data would be used to help plan treatment.

The likelihood of needing ICU care or invasive measures such as dialysis and ventilation can be suggested from the same. For example, current data is already pointing towards the need for aggressive treatment of patients with oliguric renal failure, as multiple studies have shown a correlation between that factor and mortality. Multiple literature reviews and studies have been done to find 
concrete mortality predictors of Leptospirosis. However, different factors were found to be significant in different studies despite the fact that similar parameters were assessed. Also there is a limitation in the amount of data available with the disease being prominent in countries where notification systems are still being developed and majority of the data available is retrospective.

One literature review by Rajapakse $S$, et al. evaluated 45 papers on Leptospirosis from the last twenty years to look for factors to predict mortality in the severe form of the disease. However their findings were highly variable, with mortality predictors ranging from patient characteristics including age and alcoholism, to clinical features including hemodynamic disturbances, laboratory results including leukocytosis, and complications including pulmonary involvement and renal failure [6]. Goswami RP., et al. carried out a retrospective study on 101 diagnosed Leptospirosis patients in two hospitals in Kolkata in which clinical, biochemical, demographic, and treatment related characteristics were collected. Even though initial univariate analysis suggested multiple mortality predictors such as older age, delayed antibiotic therapy, higher bilirubin, APT, ALP, WBC, and APT/ALT ratio, on using multivariate Cox regression analysis only APT/ALT ratio (HR 1.208, 95\% CI 1.051-1.388) and delay in initiation of antibiotic therapy (HR 1.208, 95\% CI 1.051-1.388) remained as significant factors [7]. Similarly, studies were undertaken in Kerala to study possible mortality predictors in Leptospirosis cases. One study was conducted in northern Kerala during a Leptospirosis epidemic by Pappachan MJ, et al. which assessed 282 laboratory confirmed cases of Leptospirosis. Mortality during this epidemic was $6.03 \%$. Even though initially on univariate analysis multiple factors were thought to be predictive of mortality, after logistic regression analysis, only presence of lung or nervous system manifestations were found to be significantly associated [8].

One of the few prospective cohort studies done was carried out by Thanachai P. et al. in Khon Kaen Thailand. One hundred and twenty-one patients with confirmed Leptospirosis were identified over a period of 6 months. Exclusion factors included patients who had other concurrent infections and children. They were followed till death or till survival two weeks post discharge. There were seventeen mortalities. After analysis using multivariate Cox regression analysis, four independent risk factors for mortality were found. They were hypotension relative risk (RR, 10.3); oliguria ( $R R, 8.8)$; hyperkalemia (RR, 5.9), and presence of pulmonary rales (RR, 5.2) [9]. As the current findings regarding mortality predictors are so varying and the majority of data is based on retrospective data, our study aims to help confirm which factors can actually be used to predict mortality through prospective data.

\section{Methods}

Study setting and patient selection- This was a prospective observational cohort study carried out over a two year period from 2014-2016 at Amrita Institute of Medical Sciences and Research Centre, Kochi, Kerala, India. Patients were identified as a clinically and serologically confirmed case of Leptospirosis. Then patient history and admission characteristics were entered as per the proforma with special attention to blood pressure levels and markers of renal failure. Patients who died after admission with diagnosis of Leptospirosis were noted. Comparison of data of those who survived and those who succumbed to the illness were compared with special respect to hypotension and oliguric renal failure. Minimal data needed included blood pressure at admission or documentation of the need for inotropic supports at admission. Also required was renal function at time of admission including urea and creatinine along with documentation of decreased urine output fitting criteria for oliguria.

Inclusion Criteria: Minimum age requirement was 18 years. There was no maximum age limit set. All patients had clinical features suggestive of Leptospirosis which was confirmed on serologically testing with IgM ELISA.

Exclusion Criteria: Patients who on initial presentation had a co-infection (eg: LRTI, UTI) as proven by blood cultures or other serological tests were excluded from this study.

Statistical methods- Based on the results on the mortality rate among Leptospirosis with respect to two important factors namely oliguria and hypotension observed in an earlier article (Prognostic factors of death in leptospirosis: a prospective cohort study in Khon Kaen, Thailand, Thanachai Panaphut, Somnuek Domrongkitchaipor 
and Bandit Thinkamrop) [9] and with 95\% confidence and $80 \%$ power, minimum sample size came to 30 for oliguria and 30 for hypotension. Patients who met the inclusion criteria were taken of which 30 had oliguria and 30 had hypotension.

Statistical analysis- Statistical analysis was done using IBM SPSS statistics, 20 windows (SPSS Inc.,
Chicago, USA). For all the continuous variables the results are given in means \pm standard deviation and for categorical variables as percentage. To compare the mean difference of numerical variable between groups Mann Whitney U test was applied. For analysis of categorical variables, Chi Square Test was used.

\section{Results}

This study on Mortality Predictors in Leptospirosis spanned from 2014 - 2016 at Amrita Institute of Medical Sciences, Kochi and included 83 patients with clinical and serological evidence of Leptospirosis. Of these, as per earlier described statistical requirements, 30 patients with hypotension were included and 30 patients with oliguric renal failure were included. Patients were divided according to their outcomes. Outcomes taken were survivor and non-survivors. There were 75 survivors and 8 non-survivors. Of these 8 non-survivors, 6 were associated with oliguric renal failure and 5 were associated with hypotension, while one was associated only with pulmonary hemorrhage.

Demographic data- On analyzing the 83 patients who were included in the study, 57 (68.7\%) were male and 26 $(31.3 \%)$ females. In this group of people, the average age was $48.5 \pm 15$ years.

Main study data- Baseline data collected on each case of Leptospirosis included epidemiological, clinical, and laboratory data. Clinical data showed that fever was the most common complaint of patients with $92.8 \%$ of patients presenting with this symptom. The next most common was myalgia (44.6\%), headache $(26.5 \%)$, and cough $(20.5 \%)$. The time it took to initiate antibiotics was also analysed and it was found that on average antibiotics were started $5.1 \pm 2.47$ days after developing symptoms. As far as clinical features went, the most frequent was renal failure. Oliguric renal failure and hypotension were present at a fixed frequency as per sample size. Icterus, crepitations and hepatomegaly were found in $31.3 \%, 28.9 \%$, and $12 \%$ respectively. Other clinical features (conjunctival suffusion, rash, rhonchi, splenomegaly, meningismus, hypo/areflexia, haemorrhage, aseptic meningitis) were present at less than $10 \%$.

Table-1: Association between different clinical features and mortality.

\begin{tabular}{|c|c|c|c|}
\hline \multirow[t]{2}{*}{ Factors } & \multirow[t]{2}{*}{ Category } & Mortality & p Value \\
\hline & & n (\%) & \\
\hline \multirow[t]{2}{*}{ Oliguric renal failure } & Yes (30) & $6(20)$ & \multirow[b]{2}{*}{0.016} \\
\hline & No $(53)$ & $2(3.8)$ & \\
\hline \multirow[t]{2}{*}{ Hypotension } & Yes (30) & $5(16.7)$ & \multirow[t]{2}{*}{0.103} \\
\hline & No (53) & $3(5.7)$ & \\
\hline \multirow[t]{2}{*}{ Fever } & Yes (77) & $7(9.1)$ & \multirow[t]{2}{*}{0.545} \\
\hline & No (6) & $1(16.7)$ & \\
\hline \multirow[t]{2}{*}{ Headache } & Yes (22) & $1(4.5)$ & \multirow[t]{2}{*}{0.345} \\
\hline & No (61) & $7(11.5)$ & \\
\hline \multirow[t]{2}{*}{ Jaundice } & Yes (9) & $2(22.2)$ & \multirow[t]{2}{*}{0.176} \\
\hline & No (74) & $6(8.1)$ & \\
\hline \multirow[t]{2}{*}{ Cough } & Yes (17) & $2(11.8)$ & \multirow[t]{2}{*}{0.739} \\
\hline & No (66) & $6(9.1)$ & \\
\hline \multirow[t]{2}{*}{ Icterus } & Yes (26) & $2(7.7)$ & \multirow[t]{2}{*}{0.685} \\
\hline & No (57) & $6(10.5)$ & \\
\hline \multirow[t]{2}{*}{ Hyporeflexia } & Yes (3) & $1(33.3)$ & \multirow[t]{2}{*}{0.157} \\
\hline & No (80) & $7(8.8)$ & \\
\hline \multirow[t]{2}{*}{ Acute renal failure } & Yes (51) & $6(11.8)$ & \multirow[t]{2}{*}{0.407} \\
\hline & No $(32)$ & $2(6.3)$ & \\
\hline
\end{tabular}


Table- 2: Association between laboratory abnormalities and mortality.

\begin{tabular}{|c|c|c|c|}
\hline \multirow[t]{2}{*}{ Factors } & \multirow[t]{2}{*}{ Category } & Mortality & \multirow[t]{2}{*}{ p Value } \\
\hline & & n (\%) & \\
\hline \multirow[t]{2}{*}{ Elevated bilirubin } & Yes (53) & $8(15.1)$ & \multirow[t]{2}{*}{0.025} \\
\hline & No (30) & $0(0)$ & \\
\hline \multirow[t]{2}{*}{ Transaminitis } & Yes (48) & $7(14.6)$ & \multirow[t]{2}{*}{0.074} \\
\hline & No (35) & $1(2.9)$ & \\
\hline \multirow[t]{2}{*}{ Hypokalemia } & Yes (25) & $1(4)$ & \multirow[t]{2}{*}{0.253} \\
\hline & No (58) & $7(12.1)$ & \\
\hline \multirow[t]{2}{*}{ Leukocytosis } & Yes (43) & $5(11.6)$ & \multirow[t]{2}{*}{0.524} \\
\hline & No (40) & $3(7.5)$ & \\
\hline \multirow[t]{2}{*}{ Anemia } & Yes (40) & $8(20)$ & \multirow[t]{2}{*}{0.002} \\
\hline & No (43) & $0(0)$ & \\
\hline \multirow[t]{2}{*}{ HemolyticAnemia } & Yes (15) & $2(13.3)$ & \multirow[t]{2}{*}{0.592} \\
\hline & No (68) & $6(8.8)$ & \\
\hline \multirow[t]{2}{*}{ Thrombocytopenia } & Yes (53) & $5(9.4)$ & \multirow[t]{2}{*}{0.933} \\
\hline & No (30) & $3(10)$ & \\
\hline
\end{tabular}

Table- 3: Association between co-morbidities and mortality.

\begin{tabular}{|c|c|c|c|}
\hline Factors & Group & Mortality & p Value \\
\hline \multirow{2}{*}{ Diabetes Mellitus } & Yes (18) & $5(27.8)$ & \multirow{2}{*}{0.003} \\
\hline & No (65) & $3(4.6)$ & \\
\hline \multirow{2}{*}{ Systemic Hypertension } & Yes (18) & $2(11.1)$ & \multirow{2}{*}{0.811} \\
\hline & No (65) & $6(9.2)$ & \\
\hline \multirow{2}{*}{ ADS } & Yes (15) & $5(33.3)$ & \multirow{2}{*}{0.001} \\
\hline & No (68) & $3(4.4)$ & \\
\hline \multirow{2}{*}{ CLD } & Yes (10) & $4(40 \%)$ & \multirow{2}{*}{0.001} \\
\hline & No (73) & $4(5.5)$ & \\
\hline \multirow{2}{*}{ Bronchial Asthma } & Yes (3) & $1(33.3)$ & \multirow{2}{*}{0.157} \\
\hline & No $(80)$ & $7(8.8)$ & \\
\hline
\end{tabular}

Table- 4: Comparison of continuous variables in survivors and non-survivors.

\begin{tabular}{|c|c|c|c|}
\hline Variable & Group & Mean \pm SD & p Value \\
\hline \multirow{2}{*}{ AGE (Years) } & Non-Survivors & $55.38 \pm 16.19$ & \multirow[t]{2}{*}{0.238} \\
\hline & Survivors & $47.77 \pm 14.87$ & \\
\hline \multirow{2}{*}{ CREATININE } & Non-Survivors & $2.61 \pm 1.22$ & \multirow[t]{2}{*}{0.472} \\
\hline & Survivors & $2.61 \pm 2.02$ & \\
\hline \multirow{2}{*}{ TOTAL BILIRUBIN } & Non-Survivors & $9.04 \pm 7.66$ & \multirow[t]{2}{*}{0.011} \\
\hline & Survivors & $3.75 \pm 5.08$ & \\
\hline \multirow{2}{*}{ AST } & Non-Survivors & $339.74 \pm 567.83$ & \multirow[t]{2}{*}{0.010} \\
\hline & Survivors & $114.83 \pm 190.32$ & \\
\hline \multirow{2}{*}{ ALT } & Non-Survivors & $137.88 \pm 161.95$ & \multirow[t]{2}{*}{0.369} \\
\hline & Survivors & $111.17 \pm 299.88$ & \\
\hline \multirow{2}{*}{ TOTAL COUNT } & Non-Survivors & $13.22 \pm 5.17$ & \multirow[t]{2}{*}{0.413} \\
\hline & Survivors & $12.58 \pm 6.38$ & \\
\hline \multirow{2}{*}{ HEMOGLOBIN } & Non-Survivors & $10.13 \pm 1.81$ & \multirow[t]{2}{*}{0.006} \\
\hline & Survivors & $12.41 \pm 2.35$ & \\
\hline \multirow{2}{*}{ PLATELETS } & Non-Survivors & $92.98 \pm 63.36$ & \multirow[t]{2}{*}{0.694} \\
\hline & Survivors & $125.31 \pm 108.09$ & \\
\hline \multirow{2}{*}{ CREATININE KINASE } & Non-Survivors & $126.18 \pm 77.66$ & \multirow[t]{2}{*}{0.554} \\
\hline & Survivors & $618.11 \pm 1517.27$ & \\
\hline
\end{tabular}




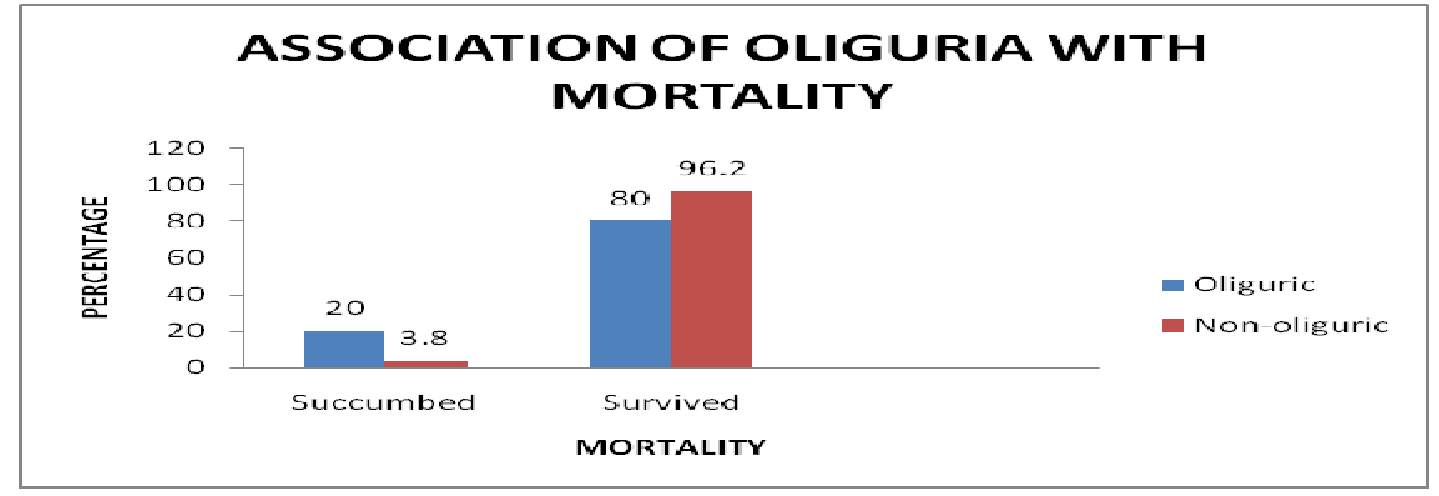

Graph-1 : Association betweenOliguria and Mortality

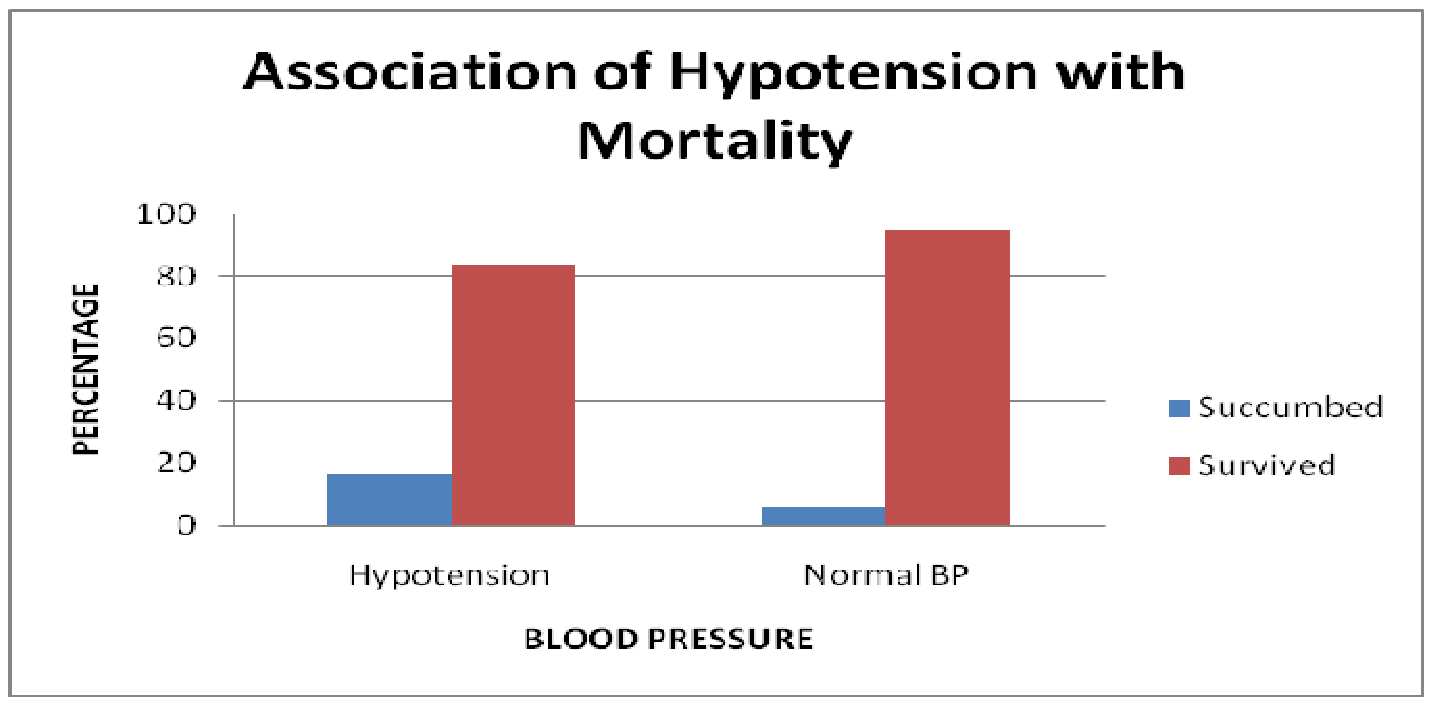

Graph-2 : Association between Hypotension and Mortality

Investigations at admission showed that even though thrombocytopenia is commonly seen as one of the main features of Leptospirosis, it was only present in $63.9 \%$ of patients at admission. Thus suspicion of Leptospirosis must start even before thrombocytopenia develops. In this particular group, elevated bilirubin was as common a feature as thrombocytopenia $(63.9 \%)$ closely followed by transaminitis $(57.8 \%)$, Leukocytosis $(51.8 \%)$ and anemia (48.2\%). Hypokalemia (30.1\%) and elevated CK (30.1\%) were also present in about $1 / 3$ of our study population.Additional investigations such as ECG and Chest x-ray were also taken. Most common abnormality in them was the presence of alveolar infiltrates on Chest $\mathrm{x}$-ray (10\%). Epidemiological characteristics such as co-morbidities were also taken into account in this study and the most common co-morbidities present in the study population were Type 2 Diabetes Mellitus (21.7\%) and Systemic Hypertension (21.7\%). Other common co-morbidities found in this set of included Alcohol Dependence Syndrome (18.1\%) and Chronic Liver Disease $(12 \%)$.

Next, association between mortality and different factors was analysed. As per the primary objectives, association between oliguric renal failure and hypotension and mortality was looked for. Of the 30 patients who presented with oliguric renal failure, $6(20 \%)$ succumbed to the illness while $24(80 \%)$ survived. Of 52 patients who presented without oliguric renal failure $2(3.8 \%)$ succumbed to the illness while $51(96.2 \%)$ survived. The $p$ value is 0.016 (i.e., $\mathrm{p}<0.05$ ) as per Chi Square test thus the association between oliguric renal failure and mortality is significant. At the same time, of the 30 patients with hypotension who were included in the study, 5 (16.7\%) succumbed to illness and $25(83.3 \%)$ survived. In patient who presented with normal blood pressure levels, $3(5.7 \%)$ died while $50(94.3 \%)$ survived. However, even though the mortality rate was higher in those with hypotension, on analysing the data with Chi-Square test, it was found to be a non-significant association since $\mathrm{p}$ value was $0.103(\mathrm{p}>0.05)$. 
Though the primary objectives of this study were to study the association between both oliguric renal failure and hypotension and mortality, data on other factors was also collected and analysed for association with death. Of these other factors, patients who had elevated bilirubin succumbed to Leptospirosis $15.1 \%$ of the time. Of those with normal bilirubin levels at presentation, all survived the illness. This association is significant as per Chi Square Test which shows a $\mathrm{p}$ value of 0.025 (i.e., $\mathrm{p}<0.05$ ). When looking for the exact values, non-survivors were found to have Mean total bilirubin of $9.044 \pm 7.661$ as compared to survivors who had a mean total bilirubin of $3.752 \pm 5.087$. That was a significant variation in the bilirubin levels with a $p$ value of 0.011 as per $t$ test. Another derangement commonly found in this study population was elevation of AST, which again showed indicated derangement in liver function. The mean AST is non-survivors was $339.74 \pm 567.830$ as compared to the $114.83 \pm 190.327$ in survivors. As per the T test, $\mathrm{p}$ value of this comparison is 0.010 making it significant. Similarly those who presented with anemia were more likely to die due to Leptospirosis. Twenty percent of the patient who presented with anemia passed away while $80 \%$ survived. However all those presented with normal hemoglobin levels survived. With a $\mathrm{p}$ value of 0.002 , this was significantly associated with mortality. The data was analysed to see exactly the difference in hemoglobin between survivors and non-survivors. In those who passed away mean hemoglobin was $10.138 \pm 1.8189$ while in those who survived it was $12.417 \pm 2.3554$. Thus a p value of 0.006 was obtained which was significant.

In this study, Type 2 Diabetes Mellitus and morality had a significant association (p value 0.003) with diabetics passing away at a rate of $27.8 \%$ while only $4.6 \%$ of non-diabetics passed away. A similar finding (significant association $\mathrm{p}$ value 0.001 ) has come for Alcohol Dependence Syndrome with one third of patients who are ethanol dependent succumbing to the illness while in those who did not consume only $4.4 \%$ succumbed. Another chronic disease which significantly increased the likelihood of mortality in Leptospirosis was Chronic Liver Disease (p value 0.001). Forty percent of CLD patients passed away while only 5.5\% of non-CLD patients succumbed.

\section{Discussion}

The purpose of this study was to find the mortality predictors of Leptospirosis. The study focused on the admission parameters of multiple patients who were later diagnosed to have Leptospirosis. Specific importance was given to the ability of hypotension or oliguric renal failure to predict mortality as a previous study had come to the conclusion that these two were the most significant factors involved in prognostication. Other baseline factors including the epidemiological, clinical features, and investigations were also analysed for significant factors. The point was to find those markers which would indicate to the admitting doctor that a patient with Leptospirosis would have a more guarded prognosis and would need closer observation. Previous studies showed a varied amount of possible risk factors for death in various populations and in various studies. The need to confirm or refute the multiple factors already proposed was an objective as well as look for any variation in the local population.

On analysis for the primary objective i.e. oliguric renal failure and hypotension, it was found that oliguric renal failure was significantly associated with mortality in Leptospirosis patients ( $p$ value 0.016) while hypotension was not significantly associated ( $p$ value 0.103 ). These two factors were chosen after reviewing multiple previous studies [9]. In this study, these two factors were found to have the most significant association with death. However, in the current study while oliguric renal failure has again been found to be a significant predictor of mortality, hypotension was not significantly associated with death. Oliguric renal failure has consistently been found as a significantly associated predictor of mortality over several literature reviews and studies [6,10, 11], as well as many other studies [12] [13] [14]. However it should be noted that none of the studies done on Leptospirosis in the same area have found oliguric renal failure to be significantly associated with mortality [8, 16]. Hypotension on the other hand, even though occasionally found to be significantly associated with death in Leptospirosis infection [6] [9] [10], is not found as often as renal failure. Previous studies in the same region as the current study have not associated it with mortality [8] [16]. In addition, the other baseline variables were also analysed and among those other significantly associated risk factors were found. These included laboratory parameters such as elevated bilirubin, anemia as well as pre-existing conditions such as Type 2 Diabetes Mellitus, Alcohol Dependence Syndrome, and Chronic Liver Disease. 
$15.1 \%$ of patients with elevated bilirubin died ( $\mathrm{p}$ value 0.025 ) with no patients with normal bilirubin passed away. The mean value of total bilirubin in non -survivors was $9.04 \pm 7.66$ as compared to the total bilirubin in survivors which was only $3.75 \pm 5.08$. Another liver function abnormality which was significantly associated with death was elevation of the liver enzymes AST. In non-survivors the mean AST was $339.74 \pm 567.83$ while in survivors it was $114.83 \pm 190.32$, with a $p$ value of 0.010 . The other laboratory parameter that could be used a mortality predictor is anemia with $20 \%$ of patients with anemia passing away due to Leptospirosis (p value 0.002 ) but in those without anemia no one passed away. Meanwhile, the mean hemoglobin of non-survivors was only $10.13 \pm 1.81$ in comparison to survivors who had a Mean hemoglobin of $12.41 \pm 2.35$ showing a significant association with a $\mathrm{p}$ value of 0.006 . Even though previous studies have suggested similar results, with features such as jaundice [12] and liver enzyme ratio [7] being significant, these factors have not been as extensively studied. Pre-existing conditions which predisposed the patients to death after Leptospira infection included Type 2 Diabetes Mellitus, Alcohol Dependence Syndrome, and Chronic Liver Disease.

Twenty-seven percent of people with Type 2 Diabetes Mellitus and Leptospirosis passed away while only 4.6\% of non-diabetics with Leptospirosis passed away. At the same time, 33.3\% of Alcohol Dependence Syndrome patients with Leptospirosis in this study passed away as compared to $4.4 \%$ of patients who did not have this illness in Chronic Liver Disease $40 \%$ of patients who had Leptospirosis died while only $5.5 \%$ patients without it died. Again, as with other secondary factors which have been found to be significant, these factors have been mentioned occasionally in other studies [6], but the association has not been extensively evaluated.

Thus this study has helped to add to the growing amount of data making oliguric renal failure one of the significant mortality predictors of Leptospirosis. While it did not confirm hypotension as a significant cause of death, it helped to find other significant variables which are as yet understudied. These results are relevant both practically as well as academically. From a practical stand point, the further re-enforcement of oliguric renal failure as one of the significant predictors of death in Leptospirosis will help admitting physicians decide on ICU care and aggressive management including need for hemodialysis. At the same time, academically, less researched variables such as anemia, Type 2 Diabetes Mellitus, etc have been found which can be the focus of future studies.

\section{Conclusion}

Oliguric renal failure is significantly associated with mortality in Leptospirosis. Other factors found to be significantly associated with mortality in Leptospirosis include elevated bilirubin, AST levels, anemia, Type 2 Diabetes Mellitus, Alcohol Dependence Syndrome, and Chronic Liver Disease. Hypotension is not significantly associated with mortality in Leptospirosis. These factors can be used to make decisions in management, including need for ICU stabilisation, by the admitting physician. Aggressive treatment of these factors can help reduce mortality in Leptospirosis. The Oliguric renal failure is a major cause of mortality in leptospirosis. Hemodialysis should be initiated in leptospirosis presenting with reduced urine output without any delay. Our study suggests an aggressive management of leptospirosis cases presenting with Oliguric renal failure. Initiating hemodialysis on immediate priority basis at the time of presentation to causality reduces the mortality rate. Close monitoring of hematology factors, liver function and renal functions should be done for effective follow upandbetter patient care.

Authors Contribution.

\begin{tabular}{|c|c|}
\hline Authors & Contribution \\
\hline Dr. Arun Divakar, M.D & \\
\hline Assistant Professor, Department of General Medicine & Study Concept, Data Analysis and Manuscript writing \\
\hline $\begin{array}{c}\text { Dr. M. Gopala Krishna Pillai, M.D } \\
\text { HOD \& Professor Department of General Medicine }\end{array}$ & $\begin{array}{c}\text { Study Concept, Data Analysis, Manuscript Review } \\
\text { and Corresponding Author }\end{array}$ \\
\hline $\begin{array}{c}\text { Dr. Elizabeth Thomas } \\
\text { Post Graduate Student (M.D ) } \\
\text { Department of General Medicine }\end{array}$ & $\begin{array}{c}\text { Study Concept, Data Analysis and Manuscript } \\
\text { writing. }\end{array}$ \\
\hline
\end{tabular}


Funding: Nil, Conflict of interest: None Permission of IRB: Yes

\section{References}

1. Haake DA, Levett PN. Leptospirosis in humans. Curr Top Microbiol Immunol. 2015;387:65-97. doi: 10.1007/978-3-662-45059-8_5.

2. Longo DL, Fauci AS, Kasper DL, et al Editors. Harrison's Principles of Internal Medicine. $19^{\text {th }}$ edition. "Infectious Diseases", "Leptospirosis" p. 1392

3. Didier Musso and Bernard La Scola. Laboratory diagnosis of Leptospirosis. A challenge. Journal of Microbiology, Immunology and Infection, 201308-01, Volume 46, Issue 4, Pages 245-252.DOI: 10. 1016/j.jmii. 2013.03.001

4. Senior K. Leptospirosis and Weil's syndrome: Cause for concern? Lancet Infectious Diseases, 2010 Dec; 10(12):823-4.

5. Walker BR, Colledge NR, Raiston SH, et al, Editors, Davidson's Principles and Practice of Medicine, 22 ${ }^{\text {nd }}$ Edition, "Infectious disease Leptospirosis" p.336-338

6. Rajapakse S, Rodrigo C, Haniffa R. Developing a clinically relevant classification to predict mortality in severe leptospirosis. J Emerg Trauma Shock. 2010 Jul; 3 (3): 213-9. doi: 10.4103/09742700. 66519 .

7. Goswami RP, Goswami RP, Basu A, Tripathi SK, Chakrabarti S, Chattopadhyay I. Predictors of mortality in leptospirosis: an observational study from two hospitals in Kolkata, eastern India. Trans R Soc Trop Med Hyg. 2014 Dec;108 (12):791-6. doi: 10.1093/trstmh/tru144. Epub 2014 Oct 30.

8. Pappachan MJ, Mathew S, Aravindan KP, Khader A, Bharghavan PV, Kareem MM, Tuteja U, Shukla J, Batra HV. Risk factors for mortality in patients with leptospirosis during an epidemic in northern Kerala. Natl Med J India. 2004 Sep-Oct; 17 (5):240-2.

9. Panaphut T, Domrongkitchaiporn S, Thinkamrop B. Prognostic factors of death in leptospirosis: a prospective cohort study in KhonKaen, Thailand. Int J Infect Dis. 2002 Mar; 6(1):52-9.

10. Prabhu M, Valsalan R, Ramachandran B., Prognostic markers and outcomes in severe leptospirosis in a tertiary hospital from south India. International Journal of Infectious Diseases, 201003-01, Volume 14, Pages e389-e389. DOI: 10.1016 / j. ijid. 2010.02.485.

11. Spichler AS, Vilaça PJ, Athanazio DA, Albuquerque JO, Buzzar M, Castro B, Seguro A, Vinetz JM. Predictors of lethality in severeleptospirosis in urban Brazil. Am J Trop Med Hyg. 2008 Dec;79(6):911-4.

12. Taylor AJ, Paris DH, Newton PN, A Systematic Review of the Mortality from Untreated Leptospirosis PLo SNegl Trop Dis - June1, 2015; 9 (6); Published: August14, 2015 https://doi.org/ $10.1371 /$ journal. pntd. 0003971

13. Ko AI, Galvão Reis M, Ribeiro Dourado CM, Johnson WD Jr, Riley LW. Urban epidemic of severe leptospirosis in Brazil. Salvador Leptospirosis Study Group. Lancet. 1999 Sep 4;354 (9181): 820-5.

14. Dupont H, Dupont-Perdrizet D, Perie JL, Zehner- Hansen S, Jarrige B, Daijardin JB. Leptospirosis: prognostic factor-sassociated with mortality. Clin Infect Dis.1997 Sep; 25(3):720-4.

15.Unnikrishnan, Dilip; Pisharody, Ramdas; Vijayalakshmy, N, Prognostic 'Factors in Leptospiroses: A study from Kerala, India, Infectious Diseases in Clinical Practice: May 2005Volume-13-Issue 3- pp 104-107

\section{How to cite this article?}

Arun Divakar, M.G.K. Pillai, Elizbeth Thomas. Clinical profile of mortality predictors in Leptospirosis:a prospective study in a tertiary care center. Int J Med Res Rev 2017;5(09):857-864.doi:10.17511/ijmrr. 2017.i09.05. 